\title{
А. А. Шевлягин
}

\section{Музейное волонтерство как механизм культурной инклюзии}

На сегодняшний день немаловажное направление социальной политики России представляет собой формирование общества равных возможностей, что соответствует процессам, происходящим в цивилизованном мире. Индикатором новой ступени развития социума является инклюзия, предполагающая создание условий для включения человека в общественную жизнь независимо от его возраста, этноса или физического состояния здоровья. Агентом инклюзии и проводником многочисленных положительных изменений в области культуры является музей. Действенным механизмом, обеспечивающим эмоциональную, психологическую и другие виды доступности музея, а также позволяющим людям активно участвовать в культуре, может стать волонтерство. В статье обобщаются способы привлечения и поиска добровольцев, на примере маломобильных лиц рассмотрены два основных пути построения взаимоотношений музей - волонтер - посетитель. На основе анализа реализованных практик преимущественно отечественных музеев произведена оценка социокультурного волонтерства и сделаны выводы о его перспективах и общественной пользе.

Ключевые слова: инклюзия, волонтер, маломобильный посетитель, музей, культура, общество, пожилой человек

\section{Arsenii A. Shevlyagin}

\section{Museum volunteering as a mechanism for cultural inclusion}

Today in Russia the formation of an equal opportunity society is an important direction of social policy, which corresponds to the processes taking place in the civilized world. The indicator of a new stage in the development of society is inclusion, suggesting the creation of conditions for a person's participation in public life, regardless of his age, ethnicity or health status. The museum is an agent of social inclusion and of numerous positive changes in the field of culture. Volunteering can become an effective mechanism for providing emotional, psychological and other types of museum accessibility, as well as allowing people to actively participate in culture. The article summarizes the ways to attract and search for volunteers, using the example of people with limited mobility. Two main ways of building mutual relations between a museum, a volunteer and a visitor are considered. Based on the analysis of the implemented practices of primarily Russian museums, an assessment of sociocultural volunteering was carried out and conclusions were drawn about its prospects and general use.

Keywords: inclusion, volunteer, visitor with limited mobility, museum, culture, society, elderly person DOI 10.30725/2619-0303-2020-4-119-124

Мировая общественность признает одним из постулатов развития цивилизованного государства его гражданскую ориентированность. Соответствие отечественной стратегии развития общества мировому уровню и названному принципу достигается постепенно за счет перемены в проводимом страной социальном курсе. Одним из его составляющих является построение общества равных возможностей для всех, которое немыслимо без внимания к проблемам человека. Показателем нового качества жизни и в то же время отражением нынешнего типа рациональности становится инклюзия [1, с. 6]. Ее идеология предполагает многоуровневую доступность для разных людей: физическую, ментальную, информативную, поведенческую, отношенческую. Поэтому создание инклюзивной среды является одним из активно формирующихся в последнее время направлений и в сфере культуры. Точками опоры инклюзивного общества становятся социокультурные институты, к числу которых относится музей.

В современном глобальном мире это учреждение характеризуется постоянным расширением своего функционала и многогранностью роли в обществе. Реагируя на требования времени, он, с одной стороны, остается территорией стабильности, сохраняет и транслирует культурное наследие, с другой - следуя своей миссии, формирует культурное поведение человека и является индикатором устойчивого социального развития [2, с. 231]. Сверх того, актуальные практики открывают для человека возможность не только пассивного восприятия культуры, но и активного участия в ней. Таким образом, музей обладает возможностями и ресурсами для преодоления проблемы культурной инклюзии, в рамках которой очерчивается комплексная задача - включение посетителей в социокультурное пространство. Отдельного вни- 


\section{А. А. Шевлягин}

мания заслуживает категория маломобильных лиц, множество которых охватывает как людей с инвалидностью, так и пожилых людей, беременных женщин и других. Одним из механизмов решения этого вопроса в отношении посетителей с ограничением подвижности может стать волонтерская деятельность в музее. Исследованию этого феномена посвящена данная статья.

Специфика вопроса предполагает междисциплинарное изучение системы музей - волонтер - маломобильный посетитель. Определение структуры взаимодействия первых двух элементов, а также выявление функций добровольцев в этом контексте основано на институциональном подходе. Направленность культурной инклюзии диктует также обращение к социокультурному подходу. В совокупности они позволяют рассмотреть волонтерство в нескольких аспектах: как фактор укрепления доверительных отношений между музеем и его аудиторией, как один из механизмов регуляции музейной деятельности, как агент личностного совершенствования человека и удовлетворения его культурных потребностей [3, с. 178]. Демографическая гетерогенность группы посетителей с ограничением подвижности предопределяет ее связь с возрастной дифференциацией волонтерства, ввиду чего возникает необходимость социологического анализа, в том числе статистических данных.

В основе волонтерского труда лежит глубокий причинно-мотивационный ряд. Зарубежные и российские исследователи по-разному определяют его компоненты, но в той или иной формулировке один из них отражает ценностно-альтруистический взгляд на мир. Он подразумевает стремление быть социально активным и полезным, помогать другим. Идеалистическая и моральная подоплека этих внутренних убеждений тесно связана со стремлением положительным образом влиять на жизнь местного населения, а также реагировать на изменения, происходящие в обществе [4]. Эта мотивация не только созвучна идеям инклюзии, но и является нравственным ориентиром социума, необходимым для реализации в нем позитивных сдвигов в восприятии другого человека. Поэтому привлечение волонтеров к работе с маломобильными посетителями на этом фоне становится не данью моде, а естественным, логическим шагом, вытекающим из сути феномена добровольчества.

Интерес к волонтерам сегодня неуклонно возрастает, о чем свидетельствует ряд значимых событий последних лет: 2018 г. был объявлен Годом волонтера, с 2017 г. было начато ежегодное празднование Дня добровольца. Организация и проведение мероприятий и проектов данной направленности получили государственную поддержку, была сформирована концепция развития добровольчества до 2025 г. [5, с. 170], в которую укладывается и программа «Волонтеры культуры», ориентированная на формирование социального института добровольчества в указанной сфере [6].

Последнее десятилетие в России ощутимый импульс к развитию получило именно культурное волонтерство, сфера действия которого распространяется и на музеи. Вопрос о принципиальной возможности и целесообразности присутствия волонтеров в этих учреждениях неоднократно поднимался на обсуждениях в ходе проведения соответствующих конференций и круглых столов, несмотря на существующий богатый положительный европейский и американский опыт. Одна из первых подобного рода конференций «Волонтеры в музее» была проведена в 2011 г. Государственным музеемзаповедником «Павловск». Помимо названной проблемы были затронуты темы прав и обязанностей волонтеров, их мотивации, обучения, обратной связи с учреждением [7]. Очень сложной задачей всегда остается определение функций, которые будут выполнять волонтеры и рациональное использование их интеллектуальных и физических ресурсов.

Сегодня круг возможной музейной деятельности волонтеров весьма широк, в ходе которой они могут найти приложение своим профессиональным знаниям и умениям. Им доверяют проведение экскурсий, совместно со штатными сотрудниками поручают разработку новых проектов, выставок, экспозиций. Чаще их задействуют в организации и сопровождении мероприятий, акций и работе с посетителями. В этом направлении еще в 2014 г. заместитель руководителя департамента культуры города Москвы Владимир Филиппов отдельно выделил помощь матерям с маленькими детьми, пенсионерам, людям с ограниченными возможностями, т. е. потенциал волонтеров в сфере взаимодействия с маломобильными людьми был замечен еще тогда, когда движение только набирало обороты [8, с. 13]. При этом массив специальностей гипотетических помощников, которые могут быть особенно полезны на этом музейном фронте, весьма разнообразен. Сюда можно отнести дефектологов, психологов, даже спортсменов, чья физическая подготовка, например, при сопровождении инвалидов-колясочников, окажется востребованной.

Но чтобы волонтерский механизм стал работать на благополучие общества и музеев, необходимо решить задачу поиска и отбора волонтеров. Для этих целей уже организована 
единая информационная сеть «Добровольцы России», в которой собраны анкеты волонтеров и база данных проводимых мероприятий. Существуют специальные целевые проекты, такие как организованный МОСгОРТУРом «Волонтер в музее», сотрудничающие с группой определенных учреждений. Также музеи, как правило, размещают на своих официальных интернетстраницах информацию о мероприятии либо о деятельности, в которой требуется помощь.

Гипотетическая ситуация участия волонтеров в деятельности музея перерастает в реальную, действенную и эффективную практику только при условии разработки полноценных программ, охватывающих несколько направлений. Вовлечение добровольцев в музейную жизнь должно быть продуманным и требует большой подготовительной работы. Сегодня многие организации готовы делиться успешными решениями в этой сфере и повсеместно передают свой накопленный, уже обобщенный опыт через Интернет. Так из составленного Политехническим музеем руководства [9] выделяется несколько блоков, предшествующих самой волонтерской программе. Первый условно можно назвать кадровым, поскольку он включает в себя выбор ответственного руководителя, который развивает программу и проектирует тренинги для сотрудников и волонтеров. Сюда также относится назначение координатора волонтеров, который отвечает за их взаимодействие, связь с музеем, прохождение обучения и т. п.

Второй этап - информационно-рекламный: он подразумевает подключение музейных служб, которые бы распространяли актуальные сведения о волонтерской программе, обеспечивая доступ к ней максимально возможному количеству людей. Сотрудники Политехнического музея выделяют три пути распределения сведений: сообщения на официальном сайте и страницах музея в популярных социальных сетях; афиши, размещаемые в библиотеках, культурных центрах и других учреждениях; сотрудничество музея с социальными центрами и фондами. Последний в целом важен для инклюзивных начинаний и позволяет привлекать к добровольчеству даже людей с особенностями физического и ментального здоровья. На сегодняшний день это крайне редкое явление, например, такой случай, был в практике Политехнического музея.

Волонтерское дело обладает низким порогом вхождения по любым демографическим признакам и уровню образования в отличие от многих других видов деятельности, а также не зависит от национальности и вероисповедания.
Несмотря на отсутствие принципиальных возрастных ограничений, в волонтерские ряды в России преимущественно вступает молодежь. Более $80 \%$ от всех волонтеров, зафиксированных в базе данных интернет-ресурса «Добровольцы России», - люди моложе 35 лет, из которых почти половина по данным на май 2020 г. приходится на студентов и рабочую молодежь от 18 до 24 лет [10]. К сожалению, процент волонтеров старше 50 лет гораздо меньше, но «серебряное» добровольчество также активно набирает обороты. В разных городах России появляются социальные центры, фонды, движения, общественные организации, занимающиеся активизацией и популяризацией этого явления [11]. Подобные примеры существуют и в музейной сфере. Показательным в этом отношении является опыт Великобритании, где по данным исследования добровольчества в сфере культуры, проведенного в 2019 г., 58 \% всех участников, выбравших эту активность люди старше 55 лет [12, р. 5].

Возрастные волонтеры, наравне с молодежью, могут выступать музейными интерпретаторами. В качестве примера интересен опыт архитектурно-этнографического музея Вологодской области «Семёнково». В 2017 г. в нем осуществлялся проект «Право на судьбу», целью которого было формирование достоверного облика северной русской деревни конца XIX в. В ходе реализации проектной деятельности была организована «Школа музейной интерпретации», которая занималась подготовкой квалифицированных волонтеров, соответствующих тематической направленности музея и способных после ее окончания транслировать культурную традицию. Конкурсный отбор в ряды единомышленников музея прошли 45 человек в возрасте от 18 до 74 лет. Такой разновозрастной подбор соответствовал идее «оживления» русской северной деревни, а гармоничное участие разных поколений добровольцев в созданных программах способствовало активизации посетительского интереса к музею. Кроме того, пожилые волонтеры часто обладают богатым жизненным опытом и навыками, которые позволяют наполнить содержанием и новыми смыслами музейную программу. В данном случае они выступали носителями местных диалектов, знатоками фольклора. С теми же, кто не обладал достаточными познаниями, сотрудники музея работали, тренируя их память, создавая для них эмоциональное погружение, тем самым осуществляя профилактику деменции [13].

Стоит отметить, что проектный, долгосрочный характер сотрудничества музея и волонтеров сегодня является одним из трендов 


\section{А. А. Шевлягин}

культурных учреждений. Учитывая современные реалии, волонтерство выходит за рамки разовых, событийных акций и сиюминутной помощи и становится стратегическим курсом музея, ориентированным на перспективу [14, c. 45]. Существуют программы, в рамках которых взаимодействие с волонтерами в летах осуществляется целенаправленно. Так в одном из проектов, реализованных в группе научных музеев Великобритании, приглашались пожилые люди с болезнью Альцгеймера. Отталкиваясь от музейного предмета, они вовлекали посетителей в диалог, стараясь при этом вызвать у них воспоминания и эмоции. По нашему мнению, для самих волонтеров положительный эффект от этой работы схож с теми результатами, которых достигали и участники проекта в Семёнково, описанного ранее. В России такого рода примеры хоть и не встречаются на каждом шагу, но количество их растет с каждым годом. Так в Государственном музее истории религии с декабря 2018 г. осуществляется проект «Волонтерское движение ГМИР», в связи с чем музеем был заключен договор о долгосрочном сотрудничестве с организацией социальной адаптации пожилых людей «Серебряный возраст» [15].

Одним из наиболее передовых в развитии волонтерских практик является Государственный Дарвиновский музей. В 2017 г. там была создана группа «Волонтеры серебряного возраста». Пожилые, социально активные граждане помогают в организации и проведении мероприятий в выходные дни, когда ощущается нехватка рабочих рук. В целом такое сотрудничество дает людям ощущение собственной значимости и полезности, позволяет через тесную связь с музеем удовлетворять сенсорный голод и потребность в личном общении, а также «сохраняет творческую молодость, приучает к активному образу жизни, расширяет кругозор» [16, с. 18].

В Дарвиновском музее, как и в Политехническом музее Москвы, Государственном Эрмитаже, ГМИИ им. Пушкина, Государственной Третьяковской галерее и некоторых других, существуют крупные центры, специализирующиеся на подготовке и распределении собственных волонтеров. Там им доверяют работу не только на разовых событиях, но в отделах музея, где они решают сложные проблемы наравне со штатными кадрами. Многолетнее сотрудничество определило устоявшиеся схемы взаимодействия Службы волонтеров Государственного Эрмитажа с другими отделами музея, например с Сектором социологических исследований, с Отделом развития и маркетинговых исследований [17]. Совместно с волонтерами эти отделы осуществляют мониторинг посетителей, что является доказательством возможности задействования музеем добровольцев для исследования аудитории и выполнения коммуникативных задач.

Подключение волонтеров к работе музея, особенно крупного, позволяет сделать ее более персонализированной и отлаженной. Волонтеры, владеющие методикой проведения социологических опросов, знающие базовые психологические основы могут выявлять проблемы, с которыми сталкивается посетитель, его потребности, ожидания от музея, анализировать поступающие запросы и транслировать их музейному руководству. Составление портрета аудитории является особенно важным на этапе разработки и адаптации программ и мероприятий.

Немаловажно, что обработка и систематизация полученных результатов и иных данных может быть выполнена удаленно. Благодаря современным технологиям эта и другие виды деятельности, такие как редакторская работа, переводы текстов, расшифровка документов и др., в теории доступны волонтерам с ограничениями в передвижении. Их труд будет оценен, а плоды работы послужат на благо музея, а через него и на пользу общества. Это один из способов вовлечь в музейную жизнь человека, который испытывает сложности в передвижении. При этом такая форма взаимодействия отнюдь не исключает общения волонтеров с музейными специалистами и наставниками. Это успешно показала практика проведения дистанционных онлайн-занятий и дискуссий в период длительного карантина 2020 г. из-за пандемии коронавируса, когда многие сотрудники культурных учреждений сами стали в некотором смысле маломобильными, лишившись возможности приходить в музей.

Помимо исследовательской функции, волонтеры также могут выполнять консультативно-информационную функцию, помогая индивидуальным посетителям в организации и планировании их перемещения по территории. Последний пункт является одной из точек приложения усилий волонтеров в Государственной Третьяковской галерее, которые помогают инклюзивному отделу и занимаются координацией туристов, в том числе с инвалидностью.

В ряду российских музеев, активно развивающих свою волонтерскую программу, стоит Музей истории ГУЛАГа. В 2013 г. при нем был открыт волонтерский центр, который носит название социально-волонтерского. Одну из категорий посетителей музея составляют жертвы политических репрессий, многие из которых одинокие люди пожилого возраста, нуждающиеся в помощи, они и являются подопечными музея. Волонте- 
ры сопровождают их в медицинские учреждения, помогают по дому, оказывают юридическую помощь и моральную поддержку, организовывают досуг [14, с. 17]. Музеем периодически организуются чаепития и обеды для подопечных, во время которых многие административно-хозяйственные функции выполняют именно волонтеры. Они же занимаются поздравлениями по праздникам, дарят цветы (например, на 8 Марта) и т. д. Хотя это далеко не единственные их обязанности, есть и те, которые связаны с музейной работой (роль смотрителя, расшифровщика записей и интервью, переводы текстов, опись предметов).

Не каждый музей имеет возможность формировать свои постоянно действующие волонтерские группы. Поэтому для социально активной деятельности музеям важно налаживать контакты также с разными некоммерческими организациями (НКО), формирующими свой волонтерский фонд. Например, упомянутый выше музей ГУЛАГа собирает под свое крыло конкретную аудиторию, к работе с которой на систематической основе подключается также сторонняя организация - медико-социальный студенческий отряд «Маленький принц». Это объединение является добровольческим движением при Волонтерском Центре Первого МГМУ им. И. М. Сеченова и занимается в основном работой с детьми и ветеранами, организовывая благотворительные сборы для детских домов, концерты для ветеранов и подопечных музея ГУЛАГа [18, с. 2].

Откликнуться на инклюзивно-волонтерское сотрудничество с музеем могут и те люди, которые работают с социальными учреждениями, обществами инвалидов, ветеранскими движениями, поскольку многое в этой деятельности является общим. Заинтересовать волонтеров можно путем поиска точек соприкосновения, для чего подойдет организация встреч и мероприятий. Например, для этих целей сотрудники Политехнического музея в Москве приглашали на экскурсию волонтеров, работающих в психоневрологическом интернате.

Волонтерство в музее - это одна из форм культуры участия, которая подразумевает «свободное, деятельное и осознанное участие людей в культурных и социальных процессах, возможность для них быть не только "потребителями" или объектами воздействия, но вносить свой вклад в принятие решений и создание культурных событий» [19, с. 14]. Использование добровольцев в работе музея расширяет его возможности, что, по нашему убеждению, приобретает особое значение для музеев, где финансирование и штат сотрудников, как правило, ограничены, а потому воплощение новых идей и проектов требует дополнительных ресурсов. Тех, кто приходит на помощь музею добровольно, нельзя считать бесплатным средством решения исключительно технических задач. К ним нужно относиться как к полноценным членам музейной команды, которых нужно готовить и обучать, но они в свою очередь смогут по-новому взглянуть на имеющиеся проблемы, предложить новые решения, привлечь новых людей и партнеров [16, с. 5]. Но чтобы волонтеры приходили и возвращались в музей, он должен стать местом реализации творческого потенциала, где могут быть предложены разнообразные задачи.

Таким образом, не претендуя на исключительность выводов, можно утверждать, что обращение музея к практике волонтерства имеет большой потенциал для развития культурной инклюзии и может стать одним из его действенных механизмов. В целом в вопросе взаимодействия с маломобильными людьми можно выделить две глобальных тенденции: улучшение качества музейной работы через более тесное взаимодействие с посетителями и приглашение к сотрудничеству волонтеров, испытывающих трудности в передвижении. Последнее направление активно развивается в русле работы с людьми «серебряного возраста», в остальном же пока имеет больше теоретический характер. Это явление позволяет решать коммуникативные, психологические и социализирующие задачи, дает возможность людям с разными возможностями здоровья приобщаться к культуре во всех ее проявлениях, а также способствует развитию толерантности и объединению социальных групп в обществе [20, с. 52].

\section{Список литературы}

1. Инклюзия как принцип современной социальной политики в сфере образования: механизмы реализации / под ред. П. Романова, Е. Ярской-Смирновой. М.: МОНФ; ЦСПГИ, 2008. 224 с.

2. Мастеница Е. Н. Социальные функции музея в глобальном мире // Труды Санкт-Петербургского государственного института культуры. 2015. Т. 210. С. 229-236.

3. Певная М. В. Дисциплинарные и методологические подходы к исследованию волонтерства // Известия Уральского федерального университета. Серия 1: Проблемы образования, науки и культуры. 2013. Т. 113, № 2. С. 174-180.

4. Сухарькова М. П. Подходы к учению мотивации участия в практиках волонтерства // Теория и практика общественного развития. 2017. № 9. С. 16-24.

5. Паклина Е. А. Развитие социальной активности волонтеров в вузе // Вестник Санкт-Петербургского государственного института культуры. 2019. № 1 (38). С. 169-172.

6. Федеральный проект «Творческие люди» // Роскультпроект. URL: https://www.roskultproekt.ru/npk/tvorcheskielyudi (дата обращения: 21.07.2020). 


\section{А. А. Шевлягин}

7. Пивоварова М. Волонтеры в музеях: зачем, как и почему? // МАРТ - технологии и маркетинг для музеев. URL: http://mart-museum.ru/mart_articles/volonteryv-muzeyah-zachem-kak-i-pochemu/ (дата обращения: 24.06.2020).

8. Козленкова Ю. В московские музеи наберут волонтеров // Известия. 2014. 21 февр., № 32 (29032).

9. Руководство по организации волонтерской программы в музее. Гл. 3. Организация волонтерской программы // ПОЛИТЕХ. URL: https://polytech.bm.digital/ article/805311560054236008/glava-3-organizatsiyavolontyorskoj-programmyi (дата обращения: 22.07.2020).

10. Аналитика волонтерства России // Единая информационная система «Добровольцы России». URL: https:// dobro.ru/analytics (дата обращения: 21.07.2020).

11. «Серебряное» добровольчество в Российской Федерации. М., 2018. 88 с.

12. Heritage volunteering survey 2019. Executive summary. SPb.: Heritage Volunteering Group, 2019. 6 p.

13. Музей-Волонтер-Общество: вызовы современности и перспективы будущего // Ассоциация менеджеров культуры. URL: http://amcult.ru/muzej-volonter-obschestvovyzovy-sovremennosti-i-perspektivy-buduschego (дата обращения: 23.07.2020).

14. Горлова Н. И., Маковецкая Д. Т. Сборник волонтерских практик в сфере культуры: метод. рекомендации. М., 2019. 124 c. URL: https://edu.dobro.ru/upload/uf/f15/f1568fba6 b5f17542744c0326752d00e.pdf (дата обращения: 23.07.2020).

15. Волонтерский центр // Государственный музей истории религии. URL: http://gmir.ru/volonterskyi_ center/ (дата обращения: 23.06.2020).

16. Волонтеры в музее / отв. ред.-сост. И. А. Гринько. М.: Благотворит. фонд В. Потанина, 2018. 54 с.

17. Шекова Е. Л. Добровольчество в сфере культуры // Некоммерческие организации в России. 2011. № 4. URL: http://www.nkor.ru/articles/2011/4/5459.html (дата обращения: 24.07.2020).

18. Куракина М. «Маленький принц» с большим сердцем // Сеченовец: Вчера. Сегодня. Завтра. Вкладка газ. «Сеченовские вести». 2019. 1 окт., № 8 (89).

19. Шляхтина Л. М. Социальные практики современного музея: границы доступности // Вопросы музеологии. 2014. № 2 (10). C. 10-15.

20. Тарасова Н. В. Волонтерская деятельность как историко-педагогический феномен // Педагогическое образование в России. 2012. № 4. С. 46-52.

\section{References}

1. Romanova P. (ed.), Jarskaja-Smirnova E. (ed.). Inclusion as a principle of modern social policy in the field of education: implementation mechanisms. M.: Moscow Public Science Foundation; Center for Social Policy and Gender Studies, 2008. 224 (in Russ.).

2. Mastenitsa E. N. Social functions of the museum in the global world. Proceedings of the Saint-Petersburg State University of Culture. 2015. 210, 229-236 (in Russ.).
3. Pevnaja M. V. The research of volunteering: disciplinary and methodological approache. Bulletin of Ural Federal University. Series 1: Issues of education, science and culture. 2013. 113 (2), 174-180 (in Russ.).

4. Sukhar'kova M. P. Approaches to studying motivation to participate in volunteer practices. Theory and practice of social development. 2017. 9, 16-24 (in Russ.).

5. Paklina E. A. Social activity of volunteers at University. Bulletin of Saint-Petersburg State University of Culture. 2019. 1 (38), 169-172 (in Russ.).

6. Federal project «Creative people». Roskultproekt. URL: https://www.roskultproekt.ru/npk/tvorcheskie-lyudi (accessed: July 21.2020) (in Russ.).

7. Pivovarova M. Volunteers at museum: what for, how and why? MART - technologies and marketing for museums. URL: http://mart-museum.ru/mart_articles/volontery-v-muzeyahzachem-kak-i-pochemu/ (accessed: June 24.2020) (in Russ.).

8. Kozlenkova Ju. Volunteers to be recruited to Moscow museums. Izvestija. 2014. Febr. 21, 32 (29032) (in Russ.).

9. A guide to organizing a volunteer program in a museum. Chap. 3. Volunteer program organization. POLITEH URL: https://polytech.bm.digital/article/805311560054236008/ glava-3-organizatsiya-volontyorskoj-programmyi (accessed: July 22.2020) (in Russ.).

10. Analytics of volunteering in Russia. Unified information system «Volunteers of Russia». URL: https://dobro.ru/ analytics (accessed: July 21.2020) (in Russ.).

11. «Silver» volunteering in Russian Federation. M., 2018. 88 (in Russ.).

12. Heritage volunteering survey 2019. Executive summary. SPb.: Heritage Volunteering Group, 2019. 6.

13. Museum - volunteer - society: challenges of our time and vision for the future. Association of Cultural Managers. URL: http://amcult.ru/muzej-volonter-obschestvovyzovy-sovremennosti-i-perspektivy-buduschego (accessed: July 23.2020) (in Russ.).

14. Gorlova N. I., Makovetskaja D. T. Collection of volunteer practices in cultural area: guidelines. M., 2019. 124. URL: https://edu.dobro.ru/upload/uf/f15/f1568fba6b5f17542744c0326752d00e.pdf (accessed: July 23.2020) (in Russ.).

15. Volunteer Center. State Museum of the History of Religion. URL: http://gmir.ru/volonterskyi_center/ (accessed: June 23.2020) (in Russ.).

16. Grin'ko I. A. (ed., comp.). Volunteer at museum. M.: V. Potanin foundation, 2018.54 (in Russ.).

17. Shekova E. L. Volunteering in the field of culture. Journal of Non-profit Making Organizations in Russia. 2011, 4. URL: http://www. nkor.ru/articles/2011/4/5459.html (accessed: July 24.2020) (in Russ.).

18. Kurakina M. «The Little Prince» with big heart. Sechenovets: Yesterday. Today. Tomorrow. Suppl. sheet of «Sechenovskie vesti». 2019. Oct. 1, 8 (89) (in Russ.).

19. Shljakhtina L. M. Social practices of the contemporary museum: the boundaries of accessibility. The Problems of Museology. 2014.2 (10), 10-15 (in Russ.).

20. Tarasova N. V. Volunteer activity as a historicalpedagogical phenomenon. Pedagogical education in Russia. 2012. 4, 46-52 (in Russ.). 